\title{
Lack of association between barotrauma and air leak in hyaline membrane disease
}

\author{
W O TARNOW-MORDI, A NARANG, AND A R WILKINSON \\ Regional Intensive Care Nursery, John Radcliffe Hospital, Oxford
}

SUMmARY A retrospective analysis of 632 infants with hyaline membrane disease admitted to this regional intensive care nursery between 1 July 1974 and 31 December 1982 showed that 387 $(61 \%)$ received mechanical ventilation. The ventilator pressures at the time the first air leak was detected were available from the records of 120 of $154(78 \%)$ of the infants who sustained pulmonary air leak. There was a significant downward trend in both peak and end expiratory pressure used during the study period. The downward trend in peak pressure persisted when inborn and outborn infants, boys and girls, and infants more than 27 , and 23 to 27 weeks' gestation were examined separately. Despite these trends there was no reduction in the incidence of pulmonary air leak in any group. These data do not support the hypothesis, implicit in the term barotrauma, that a reduction in ventilator pressures decreases the risk of air leak.

Pulmonary air leak, defined as pneumothorax, pneumomediastinum, and pneumopericardium, is a frequent complication of conventional mechanical ventilation for hyaline membrane disease.$^{1-3}$ During the first 72 hours of life the changes in cerebral haemodynamics associated with pneumothorax may precipitate periventricular haemorrhage with a consequent risk of cerebral damage. ${ }^{4-6}$ Despite improvements in the survival of infants mechanically ventilated for hyaline membrane disease since $1970,{ }^{4-9}$ the incidence of pulmonary air leak remains high. In several reports published between 1980 and 1983, pulmonary air leak occurred in 21 to $45 \%$ of newborn infants receiving mechanical ventilation. ${ }^{48-11}$

Pulmonary air leak during mechanical ventilation is usually attributed to the use of high peak inspiratory pressure ${ }^{2}$ or excessive positive end expiratory pressure. ${ }^{12} 13$ Because of this the term 'barotrauma' is sometimes used as a synonym for 'air leak'. ${ }^{13}$ Prolonged ventilator inspiratory time, ${ }^{11}$ stiff suction catheters, ${ }^{14}$ and active expiration against ventilator inflation ${ }^{15}$ have also been implicated as risk factors for pulmonary air leak. To assess the importance of peak and end expiratory pressure we have examined retrospectively the incidence of pulmonary air leak in relation to trends in ventilator pressures used in infants with hyaline membrane disease during an eight and a half year period.

\section{Patients and methods}

Patients. The records of infants admitted to the Regional Intensive Care Nursery at this hospital between 1 July 1974 and 31 December 1982 were reviewed. Hyaline membrane disease was diagnosed when expiratory grunting, nasal flaring, abnormal chest wall retractions, and a respiratory rate greater than 60 per minute were present, with an oxygen requirement increasing during the first 24 hours of life and persisting for more than 48 hours. Radiological features taken in support of the diagnosis of hyaline membrane disease were reticulo-granular or ground glass opacities with an air bronchogram on a chest radiograph taken at or after four hours of age. In infants mechanically ventilated from birth, in whom the radiological features of hyaline membrane disease may be altered, a lecithin:sphingomyelin ratio less than 1.8 in tracheal or pharyngeal fluid obtained within six hours of birth was taken as supportive evidence of the diagnosis. ${ }^{16}$

Criteria for ventilatory assistance. Indications for ventilatory assistance were (1) apnoea, (2) signs of increasing respiratory distress with failure to main-

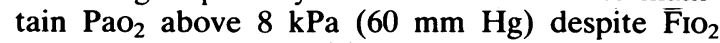
greater than $0 \cdot 6$, and (3) $\mathrm{PaCO}_{2}$ above $6.7 \mathrm{kPa}(50$ $\mathrm{mm} \mathrm{Hg}$ ). Continuous positive airways pressure was frequently used as initial ventilatory assistance during 1974-78, but less frequently from 1979-82 
particularly in infants of less than $1500 \mathrm{~g}$ birthweight. During this latter part of the study period an increasing number of infants of less than $1500 \mathrm{~g}$ birthweight who required endotracheal intubation and positive pressure ventilation after delivery and had continuing signs of respiratory failure were electively mechanically ventilated from birth. If subsequent blood gases showed that minimal ventilatory assistance was required they were quickly extubated.

Ventilators. The ventilators employed were continuous flow, time cycled, pressure limited machines (Vickers Neovent 90, Vickers Neovent 130, Bourns BP 200, and Sechrist IV 100B). In 1974 the Draeger Spiromat continuous flow and Bennett PR2 intermittent flow ventilators were also occasionally used. Ventilator pressures were recorded at the proximal airway from the ventilator pressure gauges, which were checked periodically against a water column. Bennett Cascade (models 1 and 11) and Vickers Neovent Model 90 heated water bath humidifiers were used.

Ventilation technique. At respiratory rates of 30 per minute or greater the ventilator was set at an inspiratory:expiratory ratio of $1 \cdot 0$, and only rarely was the inspiratory:expiratory ratio increased above this. At respiratory rates below 30 per minute the inspiratory:expiratory ratio was usually adjusted to give an inspiratory time of 1.0 seconds. Respiratory rates were usually set at less than 40 per minute, but faster rates were sometimes employed particularly after the acquisition of Sechrist ventilators in 1980 . The pressures used ranged between 12 and $42 \mathrm{~cm}$ $\mathrm{H}_{2} \mathrm{O}$ (peak inspiratory pressure) and 2 and $12 \mathrm{~cm} \mathrm{H}_{2} \mathrm{O}$ (end expiratory pressure). Ventilator settings and $\mathrm{F}_{\mathrm{I}} \mathrm{O}_{2}$ were adjusted to maintain arterial blood gases within the range of $\mathrm{Po}_{2} 6.7$ to $12 \mathrm{kPa}$ (50 to $90 \mathrm{~mm}$ $\mathrm{Hg}$ ) and $\mathrm{PCO}_{2} 4$ to $6 \mathrm{kPa}$ (30 to $45 \mathrm{~mm} \mathrm{Hg}$ ). After the $\mathrm{F}_{\mathrm{I}} \mathrm{O}_{2}$ had decreased to below 0.5 and the ventilator pressures reduced to 12 to $20 / 2$ to $4 \mathrm{~cm} \mathrm{H}_{2} \mathrm{O}$ infants were weaned from the ventilator by progressive reductions in respiratory rate to less than 10 per minute, followed by a period of constant positive airways pressure, then extubation. Gas flow rates of between 3 and $10 \mathrm{l} /$ minute were used and humidifiers were kept filled within the recommended limits. The temperature of the inspired gas was normally maintained between 32 and $34^{\circ} \mathrm{C}$ and always between 30 and $36^{\circ} \mathrm{C}$.

Pancuronium bromide ( 25 to $50 \mu \mathrm{g} / \mathrm{kg}$ ) was given intramuscularly or intravenously to paralyse those infants considered to be struggling excessively.

Statistical methods. Trends were analysed by Spearman's rank correlation test. Differences in proportions were examined by the $\chi^{2}$ test with Yates's correction. Means of normally distributed data were compared by Student's $t$ test. ${ }^{17}$

\section{Results}

Characteristics of the 632 infants with hyaline membrane disease admitted during the study period are shown in Table 1. A total of $197(31 \%)$ received no ventilatory assistance, $48(8 \%)$ received continuous positive airways pressure only, and $387(61 \%)$ received mechanical ventilation, sometimes preceded by a period of continuous positive airways pressure. The proportion of infants treated with mechanical ventilation steadily increased (Table 2).

Table 1 Characteristics of the 632 infants admitted to hospital with hyaline membrane disease, $1974-82$

\begin{tabular}{llll}
\hline & $\begin{array}{l}\text { Infants given no ventilatory } \\
\text { assistance }\end{array}$ & $\begin{array}{l}\text { Infants treated with } \\
\text { CPAP only }\end{array}$ & $\begin{array}{l}\text { Infants treated with } \\
\text { mechanical ventilation }\end{array}$ \\
\hline Number & 197 & 48 & 387 \\
Gestational age, mean (SD) & $34 \cdot 2$ weeks $(2 \cdot 9)$ & $32 \cdot 9$ weeks $(3 \cdot 1)$ \\
Birthweight, mean (SD) & $2206 \mathrm{~g}(637)$ & $1986 \mathrm{~g}(620)$ & $29 \cdot 9$ weeks $(3 \cdot 3)$ \\
Pneumothorax, no (\%) & $11(5 \cdot 6)$ & $6(13)$ & $1480 \mathrm{~g}(974)$ \\
Pulmonary air leak, no (\%) & $12(6)$ & $1(13)$ & $146(38)$ \\
Deaths before discharge, no (\%) & $4(2)$ & $154(40)$ & $134(35)$ \\
\hline
\end{tabular}

Table 2 The proportion of infants with hyaline membrane disease mechanically ventilated between 1974 and 1982

\begin{tabular}{|c|c|c|c|c|c|c|c|c|c|c|}
\hline Year & 1974 & 1975 & 1976 & 1977 & 1978 & 1979 & 1980 & 1981 & 1982 & Total \\
\hline $\begin{array}{l}\text { Infants with hyaline } \\
\text { membrane disease }\end{array}$ & 50 & 71 & 55 & 66 & 56 & 77 & 92 & 71 & 94 & 632 \\
\hline Mechanically ventilated & 14 & 38 & 27 & 32 & 36 & 50 & 61 & 54 & 75 & 387 \\
\hline$\%$ & 28 & 54 & 49 & 48 & 64 & 65 & 66 & 76 & 80 & 61 \\
\hline
\end{tabular}


Infants of 23 to 27 weeks' gestation with hyaline membrane disease all received mechanical ventilation except for two of the 20 admitted in 1980 .

The characteristics and outcome of the 387 mechanically ventilated infants are listed in Table 3 . There was a significant increase between 1974 and 1978 and 1979 and 1982 in the proportion of outborn infants $(\mathrm{P}<0.005)$ and of infants surviving until discharge, particularly infants of 28 to 32 weeks' gestation $(\mathbf{P}<0.001)$. The incidence of pulmonary air leak also increased from $35 \%$ to $43 \%$ between these periods but this was not statistically significant. The increase in the numbers of infants admitted, both inborn and referred, reflects the increasing demand for intensive care of the newborn during the study period.

Data on the ventilator pressures used at the time that pulmonary air leak was detected were available in 120 of $154(78 \%)$ of the infants who sustained air leak. There was a downward trend in the peak inspiratory pressure at the time of air leak in these infants $(r=-0.56, P=0.001)$. This trend persisted when infants of greater than 27 weeks' gestation (Fig. 1, $\mathrm{n}=93, \mathrm{r}=-0.57, \mathrm{P}<0.001$ ) and 23 to 27 weeks' gestation (Fig. 2, $\mathrm{n}=27, \mathrm{r}=-0.39, \mathrm{P}=0.02$ ) were examined separately. Similarly, the downward trend in peak inspiratory pressure at the time of air leak was present in both inborn $(n=79, r=-0.62$, $P=0.001)$ and outborn infants $(n=36, r=-0.48$, $P=0.001)$ and boys $(n=65, r=-0 \cdot 48, P=0.001)$ and girls $(n=50, r=-0.66, P=0 \cdot 001)$. (Data unavailable in five infants). Despite this persistent downward trend in peak inspiratory pressure no reduction in the incidence of pulmonary air leak was seen in any group. In infants of 23 to 27 weeks' gestation there

Table 3 Characteristics of the 387 infants with hyaline membrane disease mechanically ventilated in the study period. (Percentages given in parentheses)

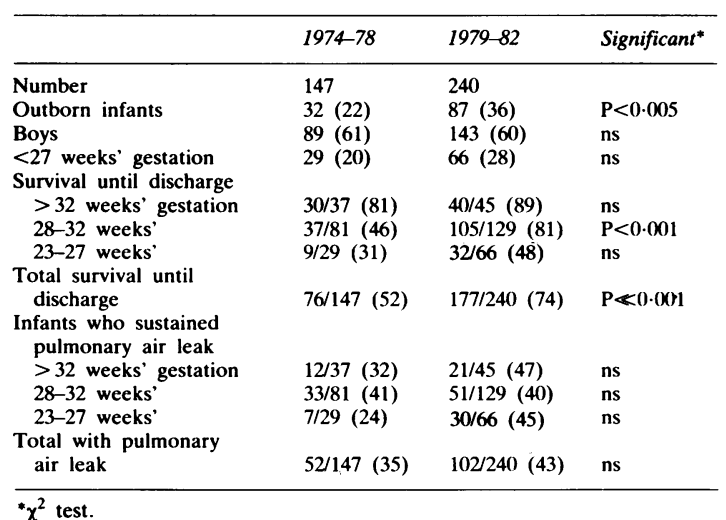
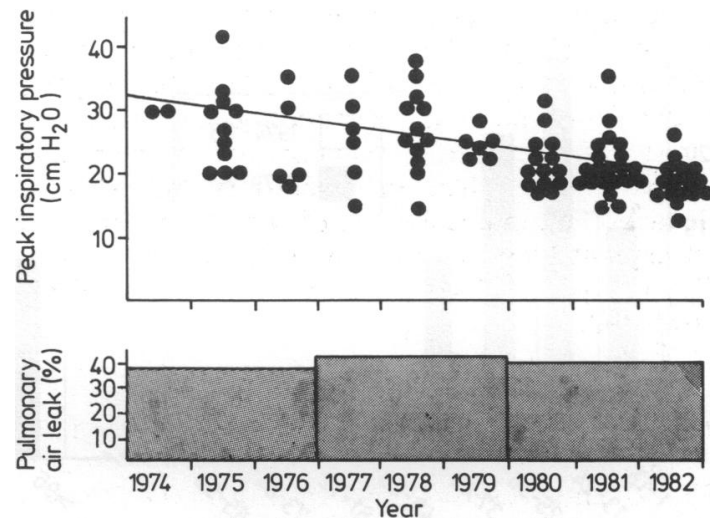

Fig. 1 Peak inspiratory pressure (PIP) at time of first air leak in babies of more than 27 weeks' gestation with hyaline membrane disease.

was a tendency towards an increased incidence of pulmonary air leak (Fig. 2).

There was also a downward trend in the positive end expiratory pressure at the time of air leak in the 120 infants for whom data were available $(r=-0 \cdot 21$, $\mathrm{P}=0.01$ ). In no group was an increasing trend in positive end expiratory pressure at time of air leak seen during the study period.

Seventy five per cent of all pulmonary air leaks in mechanically ventilated infants occurred during the first 48 hours of life (Fig. 3). Less than 10\% occurred during the period of most rapid improvement in gas exchange between 48 and 96 hours of age. ${ }^{18}$ Neither the mean age at first air leak nor the proportion of infants sustaining a first air leak before and after 48 hours of age differed significantly between 1974 and 1978, and 1979 and 1982 (mean ages 26.9 and 29.1 hours, $\mathrm{t}=-1 \cdot 41, \mathrm{n}=127$,

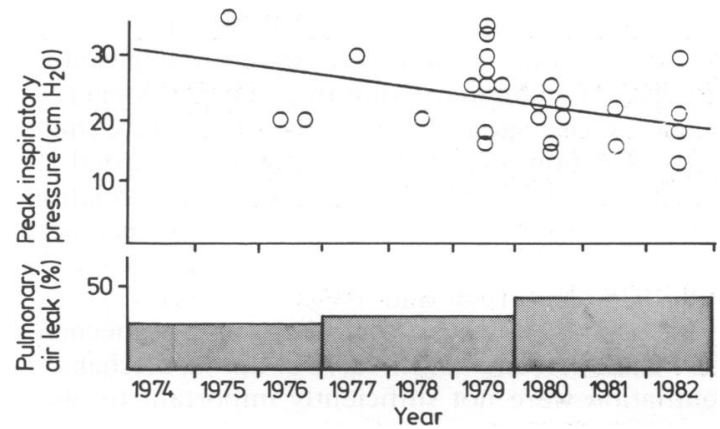

Fig. 2 Peak inspiratory pressure at time of first air leak in babies of 23 to 27 weeks' gestation with hyaline membrane disease. 


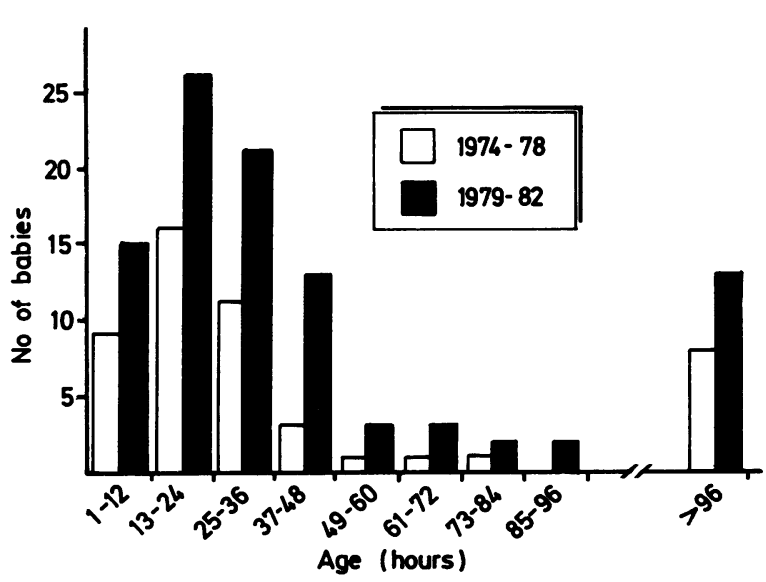

Fig. 3 Age at first air leak in babies mechanically ventilated for hyaline membrane disease.

$\mathrm{P}>0 \cdot 10$; proportions of early and later air leaks 39 of 75,3 of $\left.10, \chi^{2}=0 \cdot 24, P>0 \cdot 50\right)$.

\section{Discussion}

This study provides evidence of a progressive reduction in ventilator pressures in mechanically ventilated infants who sustained pulmonary air leak between 1974 and 1982 (Figs. 1 and 2). Other aspects of ventilator technique, particularly the inspiratory: expiratory ratio settings, did not change, which indicates that there was also a progressive reduction in mean airway pressure. Despite these trends in pressure there was no decrease in the incidence of pulmonary air leak. This was an unexpected finding, for which three reasons can be advanced. An increasing proportion of infants with hyaline membrane disease were treated with mechanical ventilation, they were treated increasingly early in the course of the disease, and a greater proportion survived (Tables 2 and 3 ). More babies in the latter part of the study period were therefore exposed to the risk of pulmonary rupture, and for longer.

The precise age in hours at the onset of mechanical ventilation and at death were not recorded. It was not therefore possible to analyse the relation between the length of exposure to mechanical ventilation and incidence of air leak between 1974 and 1978, and 1979 and 1982.

The trends, however, to earlier onset of mechanical ventilation and longer survival during mechanical ventilation were not sufficiently important to alter the distribution of age at the time of the first air leak in those two periods (Fig. 3).

We are unable to estimate the severity of disease of individual babies in terms of venous admixture and mean applied proximal airway pressure ${ }^{19}$ from the data collected. We cannot therefore exclude the possibility that in the most severely affected babies there was a reduction in incidence of pulmonary air leak during the study period which was masked by an increased incidence of air leaks in the less severely affected babies. Alternatively, in the most severely affected babies there may have been no significant trend in the pressure employed at the time of air leak over the study period. Neither possibility, however, is consistent with the observation that in infants of 23 to 27 weeks' gestation, a group likely to be at greater risk of severe hyaline membrane disease, the same trends in pressure and air leak were seen as in infants of more than 27 weeks' gestation. Our data do not support the hypothesis, implicit in the use of the term barotrauma, that reduction of ventilator pressures within the ranges employed here decreases the risk of pulmonary air leak. The reduction in pressures may, however, have contributed to the improvements in survival seen during the study period.

Reynolds and Taghizadeh have reported a comparison of the outcome for mechanically ventilated infants with hyaline membrane disease between 1967 and 1969, and 1970 and 1972. Criteria for beginning mechanical ventilation were more stringent, in terms of the severity of the disease, and it was begun later in the course of the disease than in our study. Between the two periods these authors reported a change in ventilator technique from a method employing respiratory rates of 60 to 80 per minute, inspiratory:expiratory ratio $1: 2$, and ventilator pressures of 35 to $60 / 0 \mathrm{~cm} \mathrm{H}_{2} \mathrm{O}$ to a method similar to that employed in this study, which allowed adequate oxygenation with substantially lower peak pressures and respiratory rates. This change in technique was associated with a noticeable reduction in mortality and in bronchopulmonary dysplasia characterised by fibroblastic proliferation into the lumen of terminal airways. Despite the reduction in bronchopulmonary dysplasia, there was no significant change in the incidence of pulmonary air leak between the two periods.

In a recent study Greenough observed that only mechanically ventilated infants with a specific pattern of reflex active expiratory effort against ventilator inflation developed pneumothorax. ${ }^{20}$ In a randomised trial ${ }^{15}$ one of 11 infants with reflex active expiratory effort against the ventilator who were paralysed with pancuronium developed pneumothorax while all 11 infants with this breathing pattern who were not paralysed sustained pneumothorax. The treated infants sustained a significantly lower rate of pneumothorax $(\mathrm{P}<0 \cdot 0004)$ 
despite the increase in ventilator pressures necessitated by paralysis.

These considerations lead us to suggest that the term barotrauma may be a more appropriate description of the changes represented by bronchopulmonary dysplasia than of pulmonary air leak. Current efforts to reduce the incidence of air leak in mechanically ventilated infants may benefit from a reappraisal of the role of ventilator pressure in its aetiology. A recently advanced theoretical model suggests that the inspiratory:expiratory ratio may be a major determinant of pulmonary air leak in mechanically ventilated infants. ${ }^{21}$ Perhaps pulmonary air leak and bronchopulmonary dysplasia can be minimised by a combination of a low inspiratory: expiratory ratio and low peak pressures respectively. ${ }^{22}$ The use of respiratory rates in excess of 60 per minute has also been advocated as a strategy for prevention of pneumothorax. ${ }^{23} 24$ Inadequate humidification of inspired gas may also play a role. ${ }^{25}$

Information is needed about the incidence of air leak in infants randomised, in trials of adequate size and design, to ventilation regimens that use different pressures, inspiratory:expiratory ratios, and respiratory rates. Until the results of prospective randomised studies are available we think some caution is warranted in the application of the term barotrauma to the lesions of pulmonary air leak.

We thank Miss P Townshend and her staff for their skilled nursing care, the many medical staff who contributed to this work, and Miss Belinda Moss for secretarial assistance. WT-M is an Action Research Training Fellow.

\section{References}

1 Yu VYH, Liew SW, Roberton NRC. Pneumothorax in the newborn: changing pattern. Arch Dis Child 1975;50:449-53.

2 Ogata ES, Gregory GA, Kitterman JA, Phibbs RH, Tooley WH. Pneumothorax in the respiratory distress syndrome: incidence and effect on vital signs, blood gases and $\mathrm{pH}$. Pediatrics 1976;58:177-83.

${ }^{3}$ Madansky DL, Lawson EE, Chernick V, Taeusch HW. Pneumothorax and other forms of pulmonary air leak in newborns. Am Rev Respir Dis 1979;120:729-37.

${ }^{4}$ Lipscomb AP, Thorburn RJ, Reynolds EOR, et al. Pneumothorax and cerebral haemorrhage in preterm infants. Lancet 1981;i:414-6.

5 Morgan MEI, Cooke RWI. Precipitants of neonatal periventricular haemorrhage: variability with postnatal age. In: Lucey JF, ed. 2nd special Ross Laboratories conference on perinatal intracranial hemorrhage. Washington: Ross Laboratories, 1982:60-77.

${ }^{6}$ Hill A, Perlman JM, Volpe JJ. Relationship of pncumothorax to occurrence of intraventricular hemorrhage in the premature newborn. Pediatrics 1982;69:144-9.

7 Reynolds EOR, Taghizadeh A. Improved prognosis of infants mechanically ventilated for hyaline membrane disease. Arch Dis Child 1974:49:505-15.

${ }^{8}$ Hart SM, McNair M, Gamsu H, Price JF. Pulmonary interstitial emphysema in very low birthweight infants. Arch Dis Child 1983;58:612-5.

${ }^{9}$ Lindroth M, Svenningsen NW, Ahlstrom H, Jonson B. Evaluation of mechanical ventilation in newborn infants. I Techniques and survival rates. Acta Paediatr Scand 1980;69:143-9.

${ }^{10}$ Cooke RWI, Morgan MEI, Coad NAG. Pneumothorax, mechanical ventilation and periventricular haemorrhage. Lancet $1981 ; \mathbf{i}: 555$

1 Primhak RA. Factors associated with pulmonary air leak in premature infants receiving mechanical ventilation. $J$ Pediatr 1983;102:764-8.

12 Berg TJ, Pagtakhan RD, Reed MH, Langston C, Chernick V. Bronchopulmonary dysplasia and lung rupture in hyaline membrane disease: influence of continuous distending pressure. Pediatrics 1975;55:51-4.

13 Thibeault DW. Pulmonary barotrauma: interstitial emphysema, pneumomediastinum and pneumothorax. In: Thibeault DW, Gregory GA, eds. Neonatal pulmonary care. Massachusetts: Addison-Wesley, 1979:316.

14 Newman SZ, Pomerance JJ, Brown SJ. Pneumothorax in mechanically ventilated infants associated with brand of suction catheter. Pediatr Res 1984;18:400A.

15 Greenough A, Wood S, Morley CJ, Davis JA. Pancuronium prevents pneumothoraces in ventilated premature babies who actively expire against positive pressure inflation. Lancet $1984 ; \mathbf{i}: 1-3$.

16 Jenkins PA, Baum JD. Respiratory distress syndrome. In: Wald N, ed. Antenatal and neonatal screening. Oxford: Oxford University Press, 1984:298-313.

${ }^{17}$ Nie NH, Hull CH, Jenkins JG, Steinbrenner K, Bent DH. Statistical package for the social sciences. 2nd ed. New York: McGraw-Hill, 1975.

${ }^{18}$ Engle WD, Arant BS, Wiriyathian S, Rosenfeld C. Diuresis and respiratory distress syndrome: physiologic mechanisms and therapeutic implications. J Pediatr 1983;102:912-7.

19 Rojas J, Green RS, Fannon L et al. A quantitative model for hyaline membrane disease. Pediatr Res 1982;16:35-9.

20) Greenough A, Morley C, Davis J. Interaction of spontaneous respiration with artificial ventilation in preterm babies. J Pediatr 1983;103:769-773.

21 Tarnow-Mordi WO, Tarassenko L, Wilkinson A. Pathogenesis of pneumothorax in mechanically ventilated newborn infants: a theoretical model. In: Rolfe P, ed. Fetal and neonatal physiological measurements. Vol 2. London: Butterworths, 1985.

22 Rhodes PG, Graves GR, Patel IM, Campbell SB, Blumenthal BI. Minimizing pneumothorax and bronchopulmonary dysplasia in ventilated infants with hyaline membrane disease. J Pediatr 1983;103:634-7.

${ }^{23}$ Heicher DA, Kasting DS, Harrod JR. Prospective clinical comparison of two methods for mechanical ventilation of neonates: rapid rate and short inspiratory time versus slow rate and long inspiratory time. J Pediatr 1981;98:957-61.

${ }^{24}$ Greenough A, Dixon AK, Roberton NRC. Pulmonary interstitial emphysema. Arch Dis Child 1984;59:1046-51.

25 Morrell $P$, Hey E. Morbidity and survival in neonates ventilated for the respiratory distress syndrome. $\mathrm{Br}$ Med J 1985;290: $1005-6$.

Correspondence to $\operatorname{Dr}$ A $\mathbf{R}$ Wilkinson, Neonatal Unit, John Radcliffe Hospital, Headington, Oxford OX3 9DU.

Received 28 January 1985 